\title{
Leaf Blight Disease on the Invasive Grass Microstegium vimineum Caused by a Bipolaris sp.
}

\author{
Nathan M. Kleczewski and S. Luke Flory, Department of Biology, Indiana University, 1001 East 3rd Street, \\ Bloomington, IN 47405
}

\begin{abstract}
Kleczewski, N. M., and Flory, S. L. 2010. Leaf blight disease on the invasive grass Microstegium vimineum caused by a Bipolaris sp. Plant Dis. 94:807-811.

In 2009, a previously undescribed disease was found on the nonnative invasive annual grass Microstegium vimineum (Japanese stiltgrass). Diseased plants exhibited foliar lesions, wilting, and in some cases, death of entire plants. We identified the causal agent as a Bipolaris sp. similar to B. zeicola. We observed spores and associated structures characteristic of Bipolaris spp. growing from leaf lesions on field collected plants. Pure cultures of the fungus were made and spore suspensions were applied to laboratory-reared $M$. vimineum seedlings in growth chamber and greenhouse experiments. Initial symptoms appeared on seedlings in the growth chamber experiment within $72 \mathrm{~h}$ of inoculation, and seedlings exhibited characteristic lesions within 10 days. The fungus was reisolated from lesions, and the internal transcribed spacer (ITS) region was sequenced to confirm its identity. In the greenhouse experiment, inoculated plants displayed characteristic lesions, and relatively greater spore loads increased disease incidence. Disease reduced seed head production by $40 \%$ compared to controls. This is the first report of a Bipolaris sp. causing disease on invasive $M$. vimineum. Following further analysis, including assays with co-occurring native species, this Bipolaris sp. may be considered as a biocontrol agent for invasive $M$. vimineum.
\end{abstract}

Microstegium vimineum (Trin.) A. Camus (Japanese stiltgrass) is a $\mathrm{C}_{4}$ shadetolerant annual grass that is a widespread invader of forests in the eastern United States. It is currently listed as invasive in 22 eastern states (USDA and NRCS 2005, The PLANTS Database), where it creates dense, nearly monospecific stands that have significant negative effects on native species and ecosystem functions $(7,10) . M$. vimineum rapidly invades disturbed areas such as bottomland forests, stream banks, roadsides, and forest openings $(4,12,19)$. Experimental evidence has shown that invasions can reduce native herbaceous plant biomass by up to $64 \%$ and diversity by up to $38 \%$ (10). Invaded areas also exhibit significantly different native species composition than invader-free areas (10). M. vimineum may alter ecosystem processes such as nitrogen and carbon cycling, decomposition (7), and fire re-

Corresponding author: Nathan M. Kleczewski E-mail: nklecz1980@gmail.com

* The $\boldsymbol{e}$-Xtra logo stands for "electronic extra" and indicates that two additional figures are available online.

Accepted for publication 17 March 2010.

doi:10.1094/PDIS-94-7-0807

(C) 2010 The American Phytopathological Society gimes. Although there are multiple control methods for M. vimineum $(9,14)$, it has not been economically or logistically feasible to control the progressing invasion in many areas. Biocontrol strategies for $M$. vimineum, although desirable for managing this woodland invader, have yet to be developed.

Characteristic of many invasive plants, $M$. vimineum has no known natural pathogens in its invasive range, and there is only recent evidence that it is consumed by native insects (3). Twelve pathogens have been described on $M$. vimineum in its native range. These include genera of Ascomycota (Balansia, Meliola, Phyllachora, Cerebella, and Ustilaginoidea) and Basidiomycota (Phakopsora and Puccinia; 24).

During the 2009 growing season, plants from field populations of $M$. vimineum near Arnoldsburg, WV, developed necrotic, black to brown, elongated to irregular lesions ranging from 0.1 to $2 \mathrm{~cm}$ long and 0.1 to $0.5 \mathrm{~cm}$ wide (Fig. 1A and C). Many of these lesions ran parallel to the midrib or veination. Lesion development preceded the eventual decline and death of many infected plants, and flower heads and seeds of some plants were necrotic. The incidence of symptomatic plants in affected populations often approached 80 to $100 \%$, and symptoms often appeared rapidly in previously unaffected populations. It was also observed that the disease could spread from infected $M$. vimineum to disease-free plants in nearby areas over the course of 2 weeks (R. Richardson, personal communication). The objectives of this study were to identify the causal agent of the leaf blight disease and assess its effects on $M$. vimineum reproduction.

\section{MATERIALS AND METHODS}

Isolation and identification of fungus from diseased plants. Diseased leaf tissue collected from infected $M$. vimineum at Crummies Creek Tree Farm near Arnoldsburg, WV in August 2009 was surfacedisinfested (95\% ethanol, $1 \mathrm{~min} ; 1.5 \%$ sodium hypochlorite solution, $1 \mathrm{~min} ; 95 \%$ ethanol, $1 \mathrm{~min}$; sterile deionized water, 1 min) and placed on water agar (20 g Difco agar per liter). Plates were incubated in the dark at $22^{\circ} \mathrm{C}$ for 5 days. Following incubation, leaves and spores/conidiophores were examined using light microscopy. Single spores collected from 30 diseased leaves were plated onto corn meal dextrose agar (CMDA; 15), placed under a light bank equipped with 40 -watt soft white incandescent and 40-watt soft white fluorescent lights that was set to provide a 12 -h photoperiod (100 to $125 \mathrm{~mol} \mathrm{~m}^{-2} \mathrm{~s}^{-1}$ photosynthetic photon flux density [PPFD]), as measured using an AccuPAR Linear PAR/LAI ceptometer (Decagon Devices, Inc., Pullman, WA), and incubated at $22^{\circ} \mathrm{C}$ for 10 days.

DNA was directly extracted from five isolates and sequenced using the Extract$\mathrm{N}$-Amp plant tissue extraction and polymerase chain reaction (PCR) amplification kit (Sigma Aldrich, Milwaukee, WI), and the internal transcribed spacer (ITS) region was amplified using ITS1F and ITS4 primers (11). The resulting amplicons were sequenced in the forward direction using the primer ITS1F at the Indiana University Molecular Biology Institute (Bloomington, IN). The sequences were manually inspected using Chromas Lite v2.01 software (Technyselinum Inc., Tewantin, Queensland, Australia) and compared to deposited sequences at GenBank using BLAST.

Pathogenicity test on $M$. vimineum. To determine if the isolated Bipolaris sp. was the causal agent of symptoms observed on $M$. vimineum in the field, we applied spores of the pathogen produced on CMDA plates to laboratory-grown $M$. 
vimineum seedlings. $M$. vimineum seed was collected from a population in an experiment at the Bayles Road site of the Indiana University Research and Teaching Preserve north of Bloomington, IN in 2008. Seeds were surface-disinfested $(95 \%$ ethanol, $1 \mathrm{~min} ; 1.5 \%$ sodium hypochlorite solution, $5 \mathrm{~min}$; $95 \%$ ethanol, $1 \mathrm{~min}$; sterile deionized water, $2 \mathrm{~min}$ ) and grown in autoclaved media (Metromix 360, Sun Gro Horticulture Canada Ltd.). Upon germination, seedlings were transplanted three to a pot and placed in custom-made inoculation chambers (Fig. 2). Inoculation chambers were constructed by attaching a 6-cmdiameter plastic pot within an upside-down wide-mouth mason jar (Ball Co., Muncie, IN). The pot was attached to a $9 \times 9 \times 1.25$ $\mathrm{cm}$ pine wood block with wood screws by driving screws through holes in the bottom of the pot and then through the lid of the mason jar. Plants were grown in a growth chamber equipped with fluorescent and incandescent lighting and set on a 12-h day/night cycle (day: $28^{\circ} \mathrm{C}, 90 \%$ relative humidity [RH]; night: $\left.26^{\circ} \mathrm{C}, 90 \% \mathrm{RH}\right)$ for 2 weeks. At the time of inoculation, plants were approximately 10 to $12 \mathrm{~cm}$ tall.

Conidia collected from 12-day-old Bipolaris colonies grown on CMDA were used for inoculation. The concentration of conidia in each suspension was quantified with a hemacytometer (Hausser Scientific, Horsham, PA). Conidial suspensions were diluted to a final concentration of $3.7 \times 10^{4}$ conidia $\mathrm{ml}^{-1}$. Tween 20 (Fisher Scientific, Fair Lawn, NJ) was added to all spore suspensions to achieve a final concentration of $0.02 \%$ ( $\mathrm{vol} / \mathrm{vol})$ prior to inoculation. Nine $M$. vimineum seedlings were inoculated by spraying plants until wetness with the spore suspension. Mock inoculations with a $0.02 \%$ solution of Tween 20 were applied to nine seedlings as controls.
Following inoculation, jars (tops) of inoculation chambers were affixed (Fig. 2). This allowed control plants to be separated from inoculated plants while maintaining nearly $100 \%$ relative humidity. Jars were presterilized by autoclaving, and bases/ pots were presterilized with a $15 \%$ sodium hypochlorite solution. Gas exchange was maintained in the chambers by propping the jar up with 5-mm glass rods. Plants within inoculation chambers were placed in the same growth chamber at the settings previously described. After 10 days, plants were removed from the growth chamber, and all leaves were harvested and assessed for disease incidence and severity. Disease incidence was quantified by determining the percentage of leaves with lesions for each plant. Disease severity was evaluated for leaves using the following scale: $0=$ no disease; $1=1$ to $5 \%$ of leaf surface area with lesions; $2=6$ to $10 \% ; 3=11$ to $25 \%$;

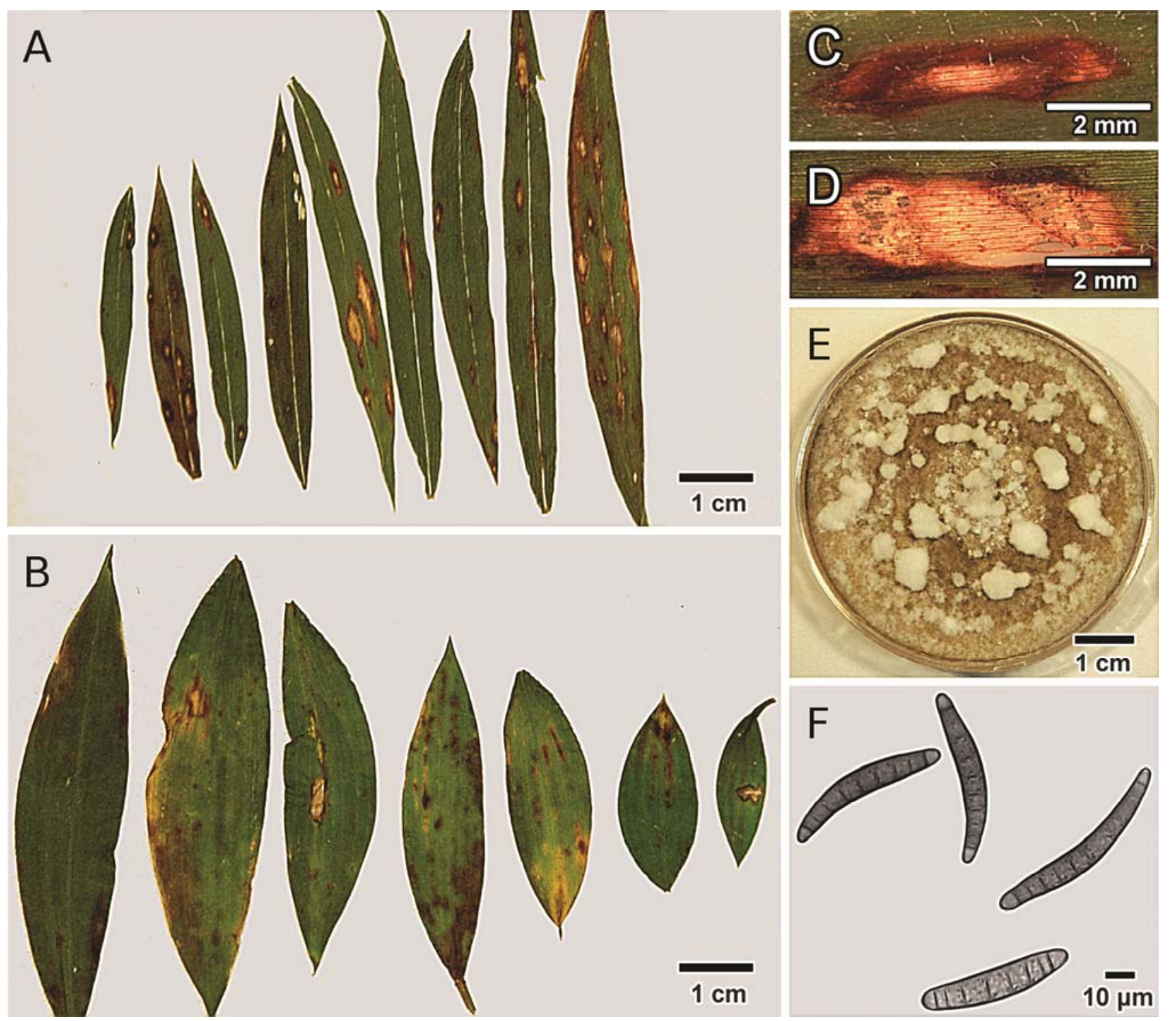

Fig. 1. Leaf blight disease symptoms on Microstegium vimineum leaves A and C, collected in the field, and $\mathbf{B}$ and D, experimentally inoculated with Bipolaris sp. Differences in leaf morphology are due to differences between field and growth chamber environmental conditions. E, Fungal cultures grown on corn meal dextrose agar placed under a light bank on a 12-h light cycle, and F, spores produced on lesions of diseased M. vimineum are characteristic of the Bipolaris group of fungi and are consistent with descriptions of B. zeicola. 
$4=26$ to $50 \%$; and $5=>50 \%$ of leaf covered by lesions. Disease severity was quantified by assigning a rating to each leaf of every plant. In order to calculate means and variances for these nonparametric data, we converted the rating values for each leaf to the midpoint of the percent leaf area with lesions (e.g., rating $2=8 \%$ ). Then, to provide a single disease severity measurement for each plant, we averaged the converted ratings for all leaves from each plant. To reisolate the fungus and confirm Koch's postulates, diseased leaves were surface-disinfested, plated on water agar, and emerging mycelia transferred to CMDA. PCR and sequencing of the ITS region of the resulting fungal cultures was carried out as previously described.

To examine the effects of fungal mycelia on symptom development, a small mycelia plug assay was carried out in parallel with the spore inoculations. Small plugs $(5 \mathrm{~mm}$ diameter, $2 \mathrm{~mm}$ thick) of 10-day-old CMDA Bipolaris cultures were applied culture-side-down to leaves on replicate seedlings. An isolate of Alternaria alternata (Fr.) Keissl isolated from $M$. vimineum leaves and a 5-mm CMDA control plug were applied to separate plants for comparison. $M$. vimineum seedlings with mycelia plugs were placed within inoculation chambers, incubated in a growth chamber under the same conditions as described previously for the conidia inoculations, and monitored daily.

Greenhouse seedling inoculations. We conducted a second experiment in the greenhouse to assess how Bipolaris inoculum levels affected disease incidence and severity and reproduction of $M$. vimineum. Bipolaris spores were collected from cultures grown on CMDA. A sterile index card was added to the top of cultures to increase sporulation (18). Spores were collected and diluted to relatively low $\left(7.8 \times 10^{3}\right.$ spores $\left.\mathrm{ml}^{-1}\right)$ and relatively high $\left(3.2 \times 10^{4}\right.$ spores $\mathrm{ml}^{-1}$ ) spore densities. M. vimineum was germinated from seed as previously described, and seedlings were grown in the greenhouse in 6-cm plastic pots. Spores were applied to $M$. vimineum by dipping five replicate plants into each spore suspension and a water control (5). To prevent cross contamination and promote pathogen growth, seedlings were then placed into separate 1-gal plastic pots lined with damp sterilized paper towels, covered with aluminum foil, and incubated at $23^{\circ} \mathrm{C}$ under ambient light. The aluminum foil was removed after $72 \mathrm{~h}$. After 10 days, disease incidence and severity were assessed as previously described. Foliar subsamples were collected, and the fungus reisolated to confirm that Bipolaris caused disease symptoms. After 40 days of plant growth, the number of seed heads produced by each plant was assessed every 3 to 4 days for 15 days.

Disease incidence (i.e., percentage of leaves diseased per plant) and disease severity were analyzed using nonparametric
Kruskal-Wallis tests (Proc NPAR1WAY, SAS Institute Inc., 2002, Cary, NC) with treatment (control, and low and high spore densities) as a fixed effect. Nonparametric tests were used because assumptions of parametric tests (e.g., ANOVA) for homogeneity of variances could not be met. Following the Kruskal-Wallis tests, WilcoxonMann-Whitney tests with Bonferroni corrections for multiple comparisons were used to evaluate differences among treatment levels. To determine if Bipolaris sp. inoculation reduced seed head production over time, the number of seed heads per plant was analyzed using repeated measures ANOVA with treatment as a fixed effect and sampling date repeated (Proc GLM, SAS Institute Inc., 2002). We report the multivariate (MANOVA) results for seed head production because assumptions of sphericity could not be met (20). We report Pillai's Trace $F$ statistic following Scheiner and Gurevitch (20).

\section{RESULTS}

Isolation and identification of fungus from diseased plants. Spores and conidiophores characteristic of a Bipolaris sp. similar to B. zeicola $(8,16)$ were prolific on lesions of most diseased leaves. Fungal spores were produced on brown to dark brown, septate conidiophores arising from darkly pigmented mycelium. On CMDA, cultures often appeared dusty to dark gray. Spores were brown to olivebrown in color, elliptical, septate, often curved, and tapering to rounded ends. Spores averaged $( \pm$ SEM $) 70.6 \pm 24.8 \mu \mathrm{m}$ in length and $13.7 \pm 2.8 \mu \mathrm{m}$ in width, with a length/width ratio of $5.0 \pm 1.4$. Sequence data from five cultures of the fungus iso-

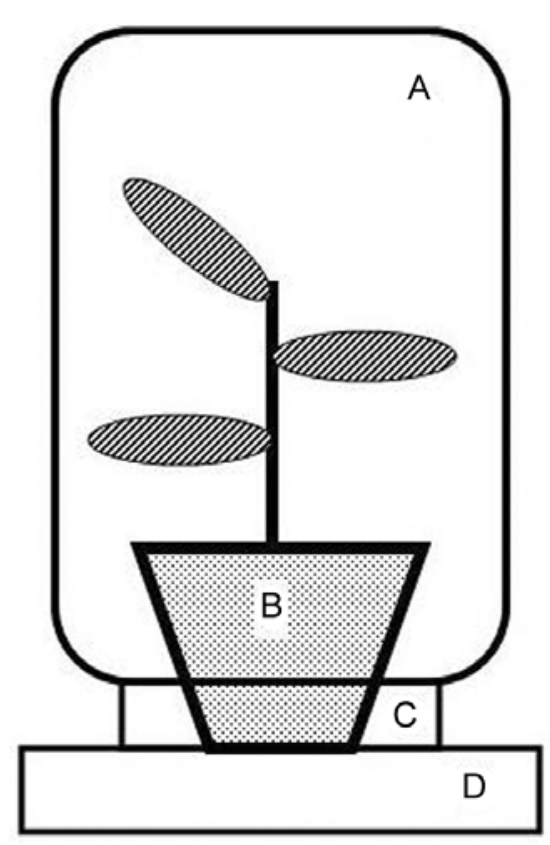

Fig. 2. Diagram of an inoculation chamber constructed of a wide-mouth mason canning jar (A), 6-cm-diameter plastic pot (B), canning jar lid (C), and $9 \times 9 \times 1.25 \mathrm{~cm}$ wood block (D). lated from lesions of field-collected $M$. vimineum matched Bipolaris zeicola (accession no. GQ167212.1; Mean bit score $955 \pm 2$; query coverage $99 \%$; E value 0.0 ). A representative sequence has been submitted to the GenBank database (GenBank accession no. GU046562).

Pathogenicity test on M. vimineum. After $72 \mathrm{~h}, M$. vimineum seedlings inoculated with conidial suspensions exhibited small black spots on multiple leaves. Spots enlarged over time and closely resembled spots observed in the field (Fig. 1C and D), although disease severity appeared lower than for field plants. Among inoculated plants, $47.4 \pm 5.14$ (mean $\pm \mathrm{SE}) \%$ of leaves displayed characteristic lesions, and the average disease severity per plant was $5.61 \pm 0.72$. Sterile Milli-Q water/Tween 20 controls did not display any disease symptoms.

After $72 \mathrm{~h}$, leaves inoculated with mycelia plugs of the Bipolaris sp. began to develop dark, irregularly shaped spots with black margins and a yellow halo. At this time, the fungus had grown through the leaves where plugs were applied, and mycelium could be seen on the bottom of inoculated leaves (Fig. 3A). After 10 days,

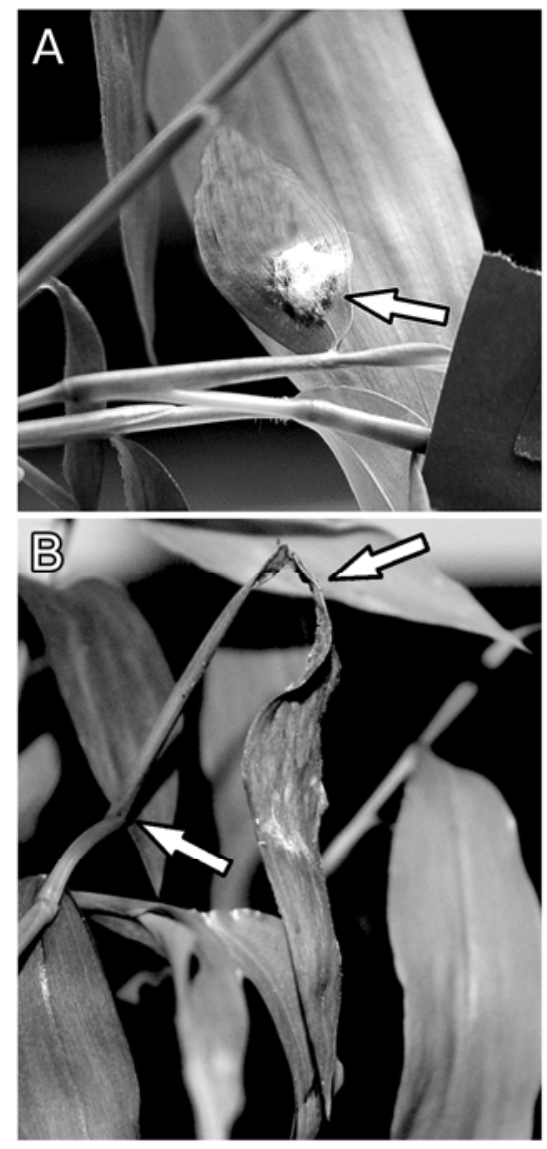

Fig. 3. Disease progression after inoculation of Microstegium vimineum leaves with mycelia plugs of Bipolaris sp. A, $72 \mathrm{~h}$, and $\mathbf{B}, 10$ days following inoculation. Within $72 \mathrm{~h}$, the fungus had grown through the leaf and could be seen on the bottom of the leaf (arrow). After 10 days, the leaf was completely dead (upper arrow) and the stem had begun to wilt and die (lower arrow). 
infected leaves were completely dead and stems were brown and wilted (Fig. 3B). Tufts of fungal mycelia could be observed emerging from infected stems. In addition, leaves adjacent to the inoculation site began to display spots and lesions similar to those on inoculated plants in the pathogenicity assay. Leaves inoculated with plugs of an Alternaria sp. and CMDA controls displayed no disease symptoms.

Greenhouse seedling inoculations. After 4 days, small brown, irregularly shaped spots with yellow halos were evident on plants receiving both the low $\left(7.8 \times 10^{3}\right.$ spores $\left.\mathrm{ml}^{-1}\right)$ and high $\left(3.2 \times 10^{4}\right.$ spores $\left.\mathrm{ml}^{-1}\right)$ spore concentrations, with no symptoms on controls. After 8 days, inoculated plants had significantly higher disease incidence (percent leaves infected; treatment: $\mathrm{H}=$ 12.99, df $=2, P=0.0015)$ and disease severity (treatment: $\mathrm{H}=12.96$, $\mathrm{df}=2, P=$ 0.0015; Fig. 4), and reduced seed head production (treatment: $\mathrm{F}_{2,12}=7.27, P=$ 0.0085; Fig. 5). The high spore density

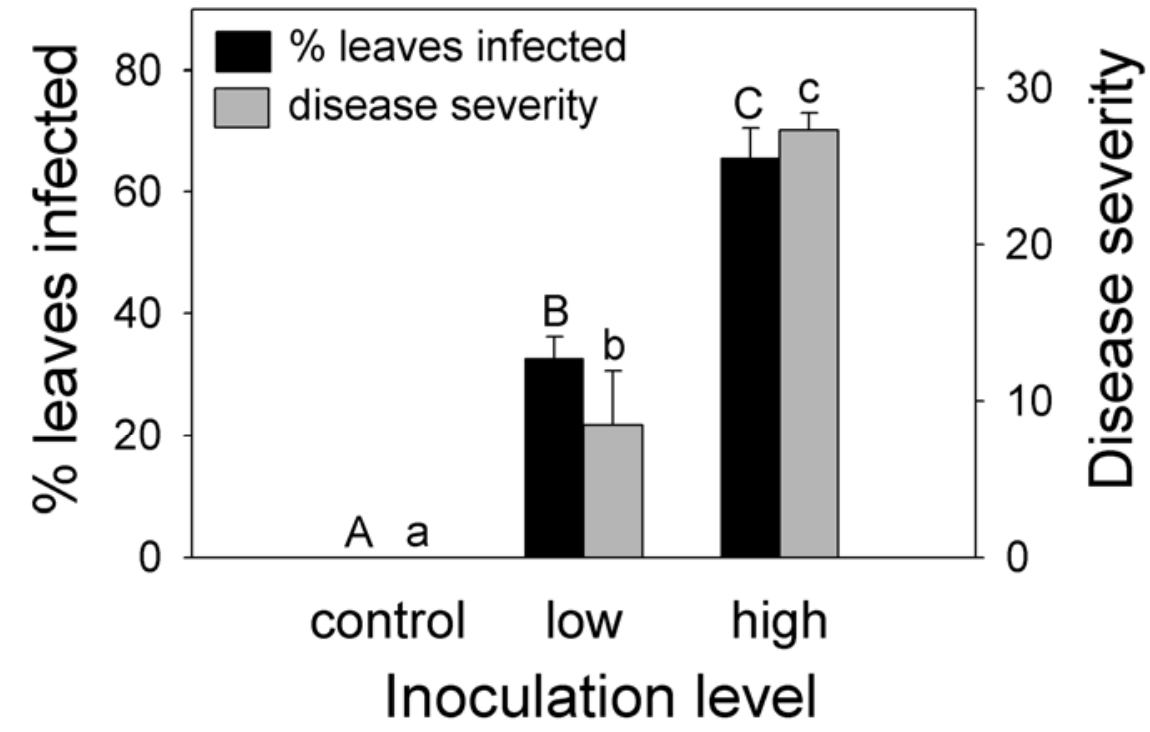

Fig. 4. Average $( \pm$ SEM) disease incidence (percent leaves infected) and disease severity of Microstegium vimineum seedlings inoculated with relatively low $\left(7.8 \times 10^{3}\right.$ spores $\left.\mathrm{ml}^{-1}\right)$ and relatively high $(3 \times$ $10^{4}$ spores $\mathrm{ml}^{-1}$ ) concentrations of Bipolaris sp. plus controls. Disease severity was quantified using the following scale: $0=$ no disease; $1=1$ to $5 \%$ of leaf surface area with lesions; $2=6$ to $10 \% ; 3=11$ to $25 \% 4=26$ to $50 \%$; and $5=>50 \%$ of leaf covered by lesions. Disease severity values were then converted to the midpoint value of the percent area with lesions. Bars with the same uppercase or lowercase letter are not significantly different.

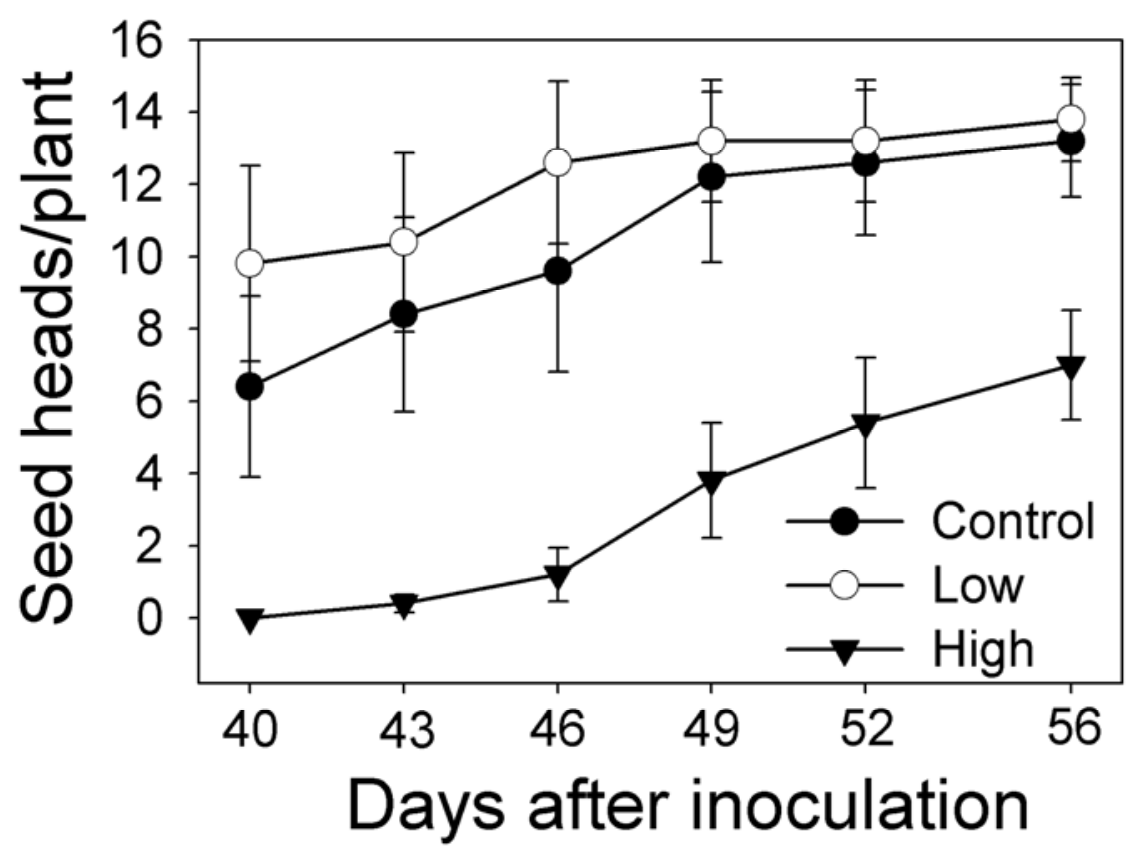

Fig. 5. Average $( \pm \mathrm{SEM})$ total number of seed heads produced by Microstegium vimineum plants inoculated with relatively low $\left(7.8 \times 10^{3}\right.$ spores $\left.\mathrm{ml}^{-1}\right)$ and relatively high $\left(3 \times 10^{4}\right.$ spores $\left.\mathrm{ml}^{-1}\right)$ concentrations of Bipolaris sp. spores plus controls over a 16-day period. resulted in $101 \%$ greater disease incidence than the low spore density (Fig. 4). The high spore density inoculation reduced $M$. vimineum seed head production by over $40 \%$ compared to control plants. Seed head production did not differ between the low spore density and the control plants $(P$ $>0.05)$. Seed head production increased over time (Pillai's Trace, $\mathrm{F}_{5,8}=9.13, P=$ 0.0037 ), but there was no interaction between sampling date and treatment (Pillai's Trace, $\mathrm{F}_{10,18}=1.87, P=0.12$, Fig. 5), indicating that the effects of disease on seed head production did not diminish over time.

Reisolation of the fungus. Reisolated fungi produced spores and conidiophores morphologically identical to those of the original field isolate used for inoculation when grown on CMDA. In addition, when the fungus was reisolated from symptomatic tissues and the ITS1F/4 regions were sequenced, BLAST results indicated cultures from experimentally inoculated seedlings were identical to that of the original isolate (accession no. GQ253958.1). The type culture of the fungus is maintained at the Indiana University of Department of Biology.

\section{DISCUSSION}

Our study shows that a Bipolaris sp. caused foliar lesions and reduced seed head production on the invasive grass $M$. vimineum. The recent outbreak of disease and eventual death of some $M$. vimineum in West Virginia appear to be due to infection by this pathogen. To our knowledge, this is the first report of a disease on invading populations of $M$. vimineum. Based on ITS sequence data and morphological analyses, the fungus isolated from lesions of field-infected $M$. vimineum is highly similar to the pathogen Bipolaris zeicola (G.L. Stout) Shoemaker (teleomorph: Cochliobolus carbonum (Nelson)), the causal organism of Northern corn leaf blight $(6,8,16,22)$. This pathogen is North American in origin, and is responsible for disease on corn worldwide (1). Studies have shown that this pathogen infects other graminaceous hosts such as Euchlaeria, Oryzae, Panicum, Paspalum, Seratia, and Sorghum $(17,21)$, and therefore may be capable of infecting $M$. vimineum. Although morphologically similar, and nearly identical in ITS sequence, further genetic analysis is required to determine the relationship between the isolates used in our study and B. zeicola.

Currently, we do not understand the epidemiology of leaf blight on $M$. vimineum in West Virginia. However, we suspect that the accumulation of $M$. vimineum thatch in invaded areas may make the grass more susceptible to Bipolaris infection by allowing high levels of Bipolaris inoculum to accumulate. Following senescence, $M$. vimineum decomposes at slower rates than native species, and a layer of thatch often 
accumulates in invaded areas (7). For example, in plots experimentally invaded with $M$. vimineum, there can be up to $120 \%$ more thatch biomass than in $M$. vimineum-free areas after 3 years of invasion (S. L. Flory, unpublished data). Pathogens in the Bipolaris genus often overwinter as mycelia and chlamydospores in thatch (1). Other factors, such as rapid growth of $M$. vimineum, particular environmental conditions, or genetically susceptible $M$. vimineum populations, may also favor fungal infection. In addition, it is possible that this pathogen has recently evolved to infect $M$. vimineum. Hybrids of different Bipolaris species commonly occur (6), and new Bipolaris pathogen races evolve rapidly $(2,6,23)$.

Adding Bipolaris sp. spores in the greenhouse experiment resulted in delayed flowering and overall reduced seed head production compared to the low spore density and control plants. As a warm season annual species, $M$. vimineum begins seed production in late summer or early fall and continues to flower and produce seed until frost kills plants. Thus, delays in seed head production for infected plants in the field could result in significantly altered M. vimineum population dynamics. In our experiments, a single spray application or dipping of $M$. vimineum seedlings did not result in plant death. Infected plants recovered from initial damage and produced new foliage. In natural populations, M. vimineum is likely exposed to multiple infection events with spore loads possibly exceeding the levels we applied to plants in the growth chamber and greenhouse experiments. Thus, the consequences of infection by this Bipolaris sp. for $M$. vimineum in the field may be much greater than what we report here. Indeed, it appears that seed production and survival of $M$. vimineum is significantly reduced in heavily diseased areas (R. Richardson, personal communication). We are currently conducting additional experiments to determine how spore loads, isolate identity/origin, environmental conditions, and host genotype alter the effects of this Bipolaris sp. on M. vimineum.

There are multiple methods that are effective for controlling $M$. vimineum invasions, such as hand-weeding or grass specific herbicides $(9,14)$, but all are either too labor intensive or too expensive to apply on a large scale. $M$. vimineum invasions may be more easily and effectively con- trolled with a biocontrol agent. The Bipolaris sp. of fungus we describe here has promise as a mycoherbicide to control this invasive grass, but more research on its biology and impacts on native and agricultural plants is needed. For example, research is needed to determine how to effectively apply inoculum and incite high levels of disease on $M$. vimineum in the field, which is a common challenge in bioherbicide research (13). Initial observations of field sites indicate that this pathogen may not have significant effects on native species, which appear to recover following the death of infected $M$. vimineum (R. Richardson, personal communication). Experiments in progress will determine conditions that optimize pathogenicity and evaluate the effects of this Bipolaris sp. on co-occurring native species.

\section{ACKNOWLEDGMENTS}

We thank R. Richardson (Crummies Creek Tree Farm) for collection of field plants, photos, and helpful discussion regarding the disease symptoms. We also acknowledge E. Pollack (Indiana University) for laboratory and greenhouse assistance, L. Rhodes (The Ohio State University) for technical guidance, M. Boehm (The Ohio State University), K. Broders (University of Guelph), and K. Clay (Indiana University) for suggestions on the manuscript, and F. Hobbs and L. Olenik for photo editing. Funding was provided by the USDA Forest Service Hoosier National Forest and a Joint Fire Science Program grant to S. L. Flory.

\section{LITERATURE CITED}

1. Anonymous. 1997. Cochliobolus carbonum. Quarantine Pests for Europe, 2nd ed. I. M. Smith, D. G. McNamara, P. R. Scott, and M. Holderness, eds. CAB International, Wallingford, UK.

2. Berbee, M. L., Pirseyedi, M., and Hubbard, S. 1999. Cochliobolus phylogenetics and the origin of known, highly virulent pathogens, inferred from ITS and glyceraldehyde-3phosphate dehydrogenase gene sequences. Mycologia 91:964-977.

3. Bradford, M. A., Devore, J. L., Maerz, J. C., McHugh, J. V., Smith, C. L., and Strickland, M. S. 2009. Native, insect herbivore communities derive a significant proportion of their carbon from a widespread invader of forest understories. Biol. Invasions. DOI 10.1007/s10530-009-9480-x.

4. Cole, P. G., and Weltzin, J. F. 2004. Environmental correlates of the distribution and abundance of Microstegium vimineum in east Tennessee. Southeast. Nat. 3:545-562.

5. Dhingra, O. D., and Sinclair, J. B. 1985. Basic Plant Pathology Methods. CRC Press, Boca Raton FL.

6. Dodd, J. L. 1993. Recent developments in the maize pathogen Bipolaris zeicola (Shoemaker) Maydica 38:201-204.

7. Ehrenfeld, J. G., Kourtev, P., and Huang, W. Z. 2001. Changes in soil functions following invasions of exotic understory plants in deciduous forests. Ecol. Appl. 11:1287-1300.

8. Ellis, M. B., and Holliday, P. 1972. Cochliobolus carbonum. CMI Descriptions of Pathogenic Fungi and Bacteria No. 349. CAB International, Wallingford, UK.

9. Flory, S. L. 2010. Management of Microstegium vimineum invasions and recovery of resident plant communities. Restor. Ecol. 18:103-112.

10. Flory, S. L., and Clay, K. 2010. Non-native grass invasion alters native plant composition in experimental communities. Biol. Invasions. DOI: $10.1007 / \mathrm{s} 10530-009-9546-9$.

11. Gardes, M., and Bruns, T. D. 1993. ITS primers with enhanced specificity for basidiomycetes application to the identification of mycorrhizae and rusts. Mol. Ecol. 2:113-118.

12. Gibson, D. J., Spyreas, G., and Benedict, J. 2002. Life history of Microstegium vimineum (Poaceae), an invasive grass in southern Illinois. J. Torrey Bot. Soc. 129:207-219.

13. Hallett, S. G. 2005. Where are the bioherbicides? Weed Sci. 53(3):404-415.

14. Judge, C. A., Neal, J. C., and Shear, T. H. 2008. Japanese stiltgrass (Microstegium vimineum) management for restoration of native plant communities. Invasive Plant Sci. Manag. 1:111-119.

15. Leuchtmann, A., and Clay, K. 1996. Isozyme evidence for host races of the fungus Atkinsonella ihypoxylon (Clavicipitaceae) infecting the Danthonia complex in the southern Appalachians. Am. J. Bot. 83:1144-1152.

16. Levic, J., and Pencic, V. 1993. Morphology of a new pathotype of Bipolaris zeicola (Stout) Shoemaker. J. Phytopathol.-Phytopathol. Z. 139:339-346.

17. Patel, B. N., and Bain, D. C. 1973. Reactions of five species of Gramineae to races $\mathrm{O}$ and $\mathrm{T}$ of Helminthosporium maydis and race 2 of $\mathrm{H}$. carbonum. Physiol. Mol. Plant Pathol. 32:283291.

18. Pratt, R. G. 2006. Enhancement of sporulation in species of Bipolaris, Curvularia, Drechslera, and Exserohilum by growth on cellulosecontaining substrates. Mycopathologica 162 133-140.

19. Redman, D. E. 1995. Distribution and habitat types for Nepal Microstegium [(Microstegium vimineum (Trin.) Camus] in Maryland and the District of Columbia. Castenea 60:270-275.

20. Scheiner, S. M., and Gurevitch, J., eds. 2001. Design and Analysis of Ecological Experiments. Oxford University Press.

21. Sivanesan, A. 1987. Graminicolous species of Bipolaris, Curvularia, Dreschlera, Exserohilum, and their teleomorphs. Mycol. Pap. 158:1-261.

22. Ullstrup, A. J. 1944. Further studies on a species of Helminthosporium parasitizing corn. Phytopathology 34:214-222.

23. Zhang, R., Wang, Q., Sun, G. Y., Mao, Q., and Gleason, M. L. 2007. First report of race 3 of Bipolaris zeicola on corn in China. Plant Dis. 91:1360.

24. Zheng, H., Wu, Y., Ding, J., Binion, D., Fu, W., and Reardon, R. 2004. Invasive plants of Asian origin established in the United States and their natural enemies. Vol. 1. U.S. Dep. Agric. For. Serv. 